\title{
Zingiber Officinale Water Extract Effect on Sperm of Alloxan-Induced Diabetic Mice: an In Vitro Examination of Sperm DNA Fragmentation, Fertilization and Embryonic Development Outcomes
}

\author{
Zena M. Hussein \\ Forensic and DNA Research and Training Centre, Al-Nahrain University, Baghdad-Iraq. \\ Corresponding author: zenamuzher@yahoo.com.
}

\begin{abstract}
Diabetes mellitus (DM) represents one of the common threats to modern global health. There are several factors increasingly encourage the occurrence of this disease for example obesity, population growth and ageing. The DM may affect male fertility at different level of functionality, by affecting on endocrine hormones that regulate spermatogenesis or affecting on spermatogenesis itself, impairing penile erection and ejaculation, reducing testosterone, increasing percentage of sperm DNA fragmentation. In fact, high level of sperm DNA fragmentation may lower natural conception, intrauterine insemination (IUI), and in vitro fertilisation (IVF) outcomes. The aim of this study was to investigate the potential therapeutic effect of water extract of Zingiber officinale (Z. officinale) roots in alloxan-induced diabetic mice on improving sperm quality and fertilization rate and early embryonic development outcomes. Male mice have subjugated for alloxan injection to induce diabetes mellitus. Diabetic males were treated with Z. officinale extract for 35 days at 50 and $100 \mathrm{mg} / \mathrm{kg}$ body weight bw. Data showed a significant enhancement in sperm parameters (count, motility and abnormal morphology), reduction of sperm DNA fragmentation rates, IVF outcomes and early embryonic development rates. In conclusion, the study suggests that $Z$. officinale possess a potential therapeutic effect to improve diabetic male with fertility problems.
\end{abstract}

[DOI: $10.22401 / \mathrm{JUNS} .21 .1 .12]$

Keywords: Diabetic mellitus, Zingiber officinale, DNA fragmentation, IVF, Early embryonic development.

\section{Introduction}

Diabetes mellitus (DM) represents one of the common threats to modern global health. Based on report released by the World Health Organization (WHO) that globally, 422 million adults aged over 18 years were living with diabetes in 2014 [1].The complications of DM can harshly impact the finances of individuals and their families, and the economies of nations [2]. There are several factors increasingly encourage the occurrence of this disease for example obesity, population growth and ageing [3].

The DM may affect male fertility at different level of functionality, by affecting on endocrine hormones that regulate spermatogenesis or affecting on spermatogenesis itself, impairing penile erection and ejaculation, reducing testosterone, increasing percentage of sperm DNA fragmentation [2,4,5]. Based on animal model studies, sperm DNA fragmentation disorder plays a significant role in sperm fertilizing capacity, embryonic development and/or pregnancies [6,7]. In fact, high level of sperm DNA fragmentation may lower natural conception, intrauterine insemination (IUI), and in vitro fertilisation (IVF) outcomes [8,9].

Several studies suggested that treatment with natural antioxidants such as vitamins $\mathrm{C}$ and $\mathrm{E}$, zinc, selenium, folate, carnitine and carotenoids may improve male fertility. The improvement in male fertility was ascribed to the fact that these antioxidants can provide a protective effect on sperm DNA from oxidative stress and damage, which could significantly improve sperm quality, and hence increase reproductive efficiency (i.e. rate of fertility) [10, 11] and also improve the outcomes of IVF and intracytoplasmic sperm injection (ICSI) [12].

Recently, researchers have investigated the potential effect of Zingiber officinale (Z. officinale) in enhancing fertility in diabetic male as it possesses anti-diabetic activity $[10,13]$. Zingiber officinale belongs to the family (Zingiberaceae) and it is characterised by its anti-inflammatory, hypoglycemic, anti- 
apoptotic, androgenic and antioxidant properties [14]. In fact, the expression of these biological activities is related to the presence of various potentially bioactive substances such as zingerone, gingerdiol, zingibrene, gingerols and shogaols [15].

Several studies have investigated the hypoglycaemic effect of of $Z$. officinale in both animals and human. These studies have focused on the role of the extract on reducing the level of glucose in blood and how such decrease in this level, could improve sperm quality such as reducing sperm DNA fragmentation and enhancing sperm motility $[16,17]$. However up till now there is no study investigate. The capacity of sperms for fertilizing eggs in IVF and evaluating the quality of early embryonic developmental rate after treatment with $Z$. officinale extract. Therefore, this study has investigated for the first time the beneficial effect of $Z$. officinale aqueous extract in reducing sperm DNA fragmentation and enhancing the IVF outcome rates and embryonic developmental rates. Such investigation can bring the benefit for diabetic patients looking for improving their fertility quality rate as well as for improving their life quality, since the preparation of this aqueous extract is cheap and can administrated doses safely with no fair of any side effect compared to the treatment using drug which can be expensive and has side effect at high doses.

\section{Materials and Methods Extract Preparation}

Fresh rhizomes (Zingiber officnale) were purchased from local markets. The extraction was prepared following pervious protocol provided by Sutyarso et al., (2016) [18] with slight modification. Briefly, the ginger rhizome was air-dried then ground with an electric grinder to obtain the powder. The maceration method was used for the extract preparation, by mixing $50 \mathrm{~g}$ of plant powder with $250 \mathrm{ml}$ of distilled water and left for 48 hours at room temperature. Following the incubation period, the macerate was filtered and evaporated at $40-50^{\circ} \mathrm{C}$ until light brown extract was released. The extract was stored in air-tight container in a refrigerator.

\section{Experimental Design}

Fifty adult albino mice (40 males and 10 females), weighing between 25-35 g, were obtained from the Biotechnology Research Center at Al-Nahrain University where the study has been done. The mice were kept at a temperature of $21 \pm 1^{\circ} \mathrm{C}$ and $12 \mathrm{hrs}$ light/dark cycle, with free access to food and water. Prior to diabetes induction with alloxan (Sigma Aldrich, UK), all male mice in experimental groups were fasted for $48 \mathrm{hrs}$. The males were randomly divided into four groups of 10 animals each. The first group (G1) was given normal saline as a negative control group, and the other three groups inducted with alloxan by intraperitoneal injection of a single daily dose of $150 \mathrm{mg} / \mathrm{kg}$ (bw) for 3 days to induce diabetes [19]. The three diabetic groups were divided as following; a group kept as a diabetic control which was positive control group (G2) whereas the other two groups treated with $Z$. officnale extract which was divided either as low dose $50 \mathrm{mg} / \mathrm{kg}$ was labelled as (G3) or high dose group $100 \mathrm{mg} / \mathrm{kg}$ which was labelled as (G4) for 35 days. Following $72 \mathrm{hrs}$ after alloxan injection the diabetes was confirmed in these groups. Using glucose enzymatic kit (Spin React, Spain), the serum glucose level was measured in blood samples. Mice having $200 \mathrm{mg} / \mathrm{dl}$ of serum glucose were selected in this study and considered as diabetics [20].

\section{Testosterone Assay}

Blood samples were collected via cardiac puncture before sacrificing the animals in each group to determine the level of testosterone. Blood samples were spun at $2500 \mathrm{rpm}$ for 10 minutes in centrifuge, to separate serum from whole blood. The concentration of testosterone was measured using enzyme linked immunoassay (ELISA) kit (Monobind Inc. USA).

\section{Preparation of Spermatozoa}

At day 35, mice were sacrificed by cervical dislocation. The cauda epididymis from male was removed and quickly transferred to a culture dish containing $500 \mu$ tissue culture medium (TCM-199 (Sigma, USA). An incisions was made in the cauda epididymis, followed by gentle squeezing by using fine forceps to allow spermatozoa to swim out into 
the culture medium. Spermatozoa were left to disperse for 2-3 $\mathrm{min}$. at room temperature. Before incubation, sperm samples were assessed for matching the sperm parameters and DNA fragmentation using acridine orange stain. For the purpose of IVF, sperm sample suspensions were taken after $1.5 \mathrm{hrs}$ of incubation at $37^{\circ} \mathrm{C}$ in $5 \% \mathrm{CO}_{2}$ incubator, sperms have left for this period of time to allow sperm for activation.

\section{Microscopic Examination}

Sperm samples were assessed according to the parameters provided by world health organization laboratory manual [21], these include; sperm count using Makler counting chamber (VWR, UK), sperm motility and sperm abnormalities using Eosin Nigrosin stain.

\section{Acridine Orange Test}

Acridine Orange staining was performed according to the protocol provided by Tejada et al., (1984) and Talebi et al., (2012) [22, 23]. Briefly, the smears were made on the slides and allowed to air-dried and then fixed in Carnoy's solution (methanol:acetic acid, 3:1) at $4^{\circ} \mathrm{C}$ and left overnight . Each slide was stained with freshly prepared AO $(0.19 \mathrm{mg} / \mathrm{ml}$ in $0.1 \mathrm{M}$ citric acid and $0.3 \mathrm{Na} 2 \mathrm{HPO} 47 \mathrm{H} 2 \mathrm{O}$, $\mathrm{pH} 4$ ) for 10 minutes. Smears were assessed on the same day using fluorescent microscope (Zeiss Co., Germany) with a $460 \mathrm{~nm}$. Acridine orange emitted green fluorescent when it bind to DNA (double stranded), whereas the stain emitted red fluorescent when it bind to fragmented DNA (single stranded).

\section{Oocytes Preparation}

Adult female mice were induced for superovulation by injection of 10 I.U. of pregnant mare serum gonadotropin (PMSG) (Folligon®, Intervet, Holland), followed by injection of 10 I.U. of (hCG) (Chorulon ${ }^{\circledR}$, Intervet, Holland), 42-48 hrs later. Female mice were sacrificed by cervical dislocation. $12 \pm 2$ hrs post- hCG injection [24]. Oviducts were collected and oocyte were recovered after inducing an incision in the ampulla region of each oviduct using 25 -gauge needle to release the cumulus oocytes complexes (COCs). COCs were transferred into insemination drops $(200 \mu 1$ of TCM-199 medium) and incubated in $5 \% \quad \mathrm{CO}_{2}$ incubator at $37^{\circ} \mathrm{C}$. Only mature and morphologically normal oocytes were selected for culture.

\section{In Vitro Fertilization}

Capacitated spermatozoa at density $1-2 \times 10^{6} / \mathrm{ml}$ were added to each insemination droplet which had 4 oocytes. Sperms and oocytes were overlaid with mineral oil in culture dish and incubated for 4-6 hrs at $37^{\circ} \mathrm{C}$ in a humidified atmosphere of $5 \%$ $\mathrm{CO}_{2}$ incubator for fertilization. Following incubation, the inseminated oocytes were washed several times with HEPES-buffer Earle's medium followed by at least one wash with buffer Earle's medium, and then transfered into $50 \mu \mathrm{l}$ droplet of the same medium. The dishes were incubated at $37^{\circ} \mathrm{C}$ in a humidified $5 \% \mathrm{CO}_{2}$ incubator overnight.

\section{Assessment of Fertilization and Embryonic Development}

The assessment of fertilized oocyte was indicated based on the presence of two pronuclei 16-18 hrs post-insemination. The presence of pronuclei is an indicator for normal fertilization. The assessment of embryonic development was indicated by the number of cleavage cells, normal embryonic development showed 2-4 cell embryos after $24 \mathrm{hrs}$ of IVF.

\section{Statistical Analysis}

Statistical analysis were performed with SPSS software (version 16). Data were analyzed using Chi-square and ANOVA- test. $\mathrm{P} \leq 0.05$ was considered statistically significant. Data was presented as mean \pm standard error of the mean (SEM).

\section{Results}

The Measurement of Testosterone Hormone levels Following Oral Administration with the Extract

Following the DM induction in male mice by intraperitoneal injection of alloxan, testosterone hormone level was measured after 35 days in all animal groups. Interestingly, the results showed that both low dose group G3and high dose group G4 had a significant effect on enhancing testosterone level after oral administration of $Z$. officinalet extract when compared with negative control group 
G2. There was no significant difference between the effect of both low and high dose groups when compared with positive control G1 Table (1).

\section{Evaluation of Sperm Parameters Following Oral Administration with the Extract}

The results of assessment of the sperm count had showed that the high dose group G4 and low dose group G3 had significant effect when compared with negative control G2. The data on the assessment of sperm motility suggested that both low dose group G3 and high dose group G4 significantly promoted sperm motility when compared with the negative group $\mathrm{G} 2$. The data on the assessment of sperm morphology abnormalities suggested that high dose group $\mathrm{G} 4$ had significant effect on reducing sperm morphology abnormalities when compared with the negative group G2. Also, low dose group G3 had significantly reduced the sperm morphology abnormalities when compared with the negative control G2 Table (2).

\section{The Rate of Sperm DNA Fragmentation Following Oral Administration with the Extract}

The DNA fragmentation was assessed in sperm sample of all male groups using $\mathrm{AO}$ stain. In this assay the fragmented sperm has emitted red florescence as indicator on single DNA strand, whereas, normal sperm has emitted green florescence as an indicator on the presence of double DNA strands Fig.(1). The percentage of sperm DNA fragmentation was measured. The gathered data showed that the high dose group G4 and low dose group G3 had significant effect on reducing sperm DNA fragmentation rate after oral administration of $Z$. officinale over 35 days of treatment when compared with and negative controls group Table (3).

\section{The Assessment of Fertilization Rate and Early Embryonic Development Outcomes Following Oral Administration with the Extract}

The rate of fertilisation was measured by calculating the rate of healthy and normal developed fertilised oocytes. Data showed that the $Z$. officinale had significant increase in the percentage of fertilised oocytes in both high dose group G4 and low dose group G3 when compared with the negative control group. The rate of early embryonic development was determined by calculating the rate of presence healthy and normal 2-4 cells. Data showed that all embryo in all groups have the capacity to develop into early stages of embryonic life. There was no differences in the rates between treated groups and controls.

\section{Discussion}

Male fertility is significantly affected by DM in men at reproductive age. Particularly, in male patients that DM have either not been well controlled or has been present for many years. Infertility in diabetic male can cause for number of issues these including; erectile dysfunction, retarded ejaculation (delayed ejaculation), retrograde ejaculation, reduced sperm quality and hypogonadism (low testosterone) $[4,25,26]$. Conventional therapy for DM is commonly by uptake of insulin which in high doses may have side effect. Recently researchers intensively investigated the beneficial effect of plant extract such as $Z$. officinale, as an alternative natural therapy for DM due to its advantages properties. Several studies suggested that $Z$. officinale in its different forms has a broad safety features. Rong et al., (2009) have investigated the high dose toxicity of ginger in both male and female rates. They suggested in their study that the administration of ginger powder up to $2000 \mathrm{mg} / \mathrm{kg}$ body weight by a gavage method over 35 days has not associated with any mortalities and abnormalities in general conditions, behaviour, growth, and food and water consumption [27]. Similarly Shalaby and Hamowieh, (2010) suggested that the administration of acute oral LD50 of methanolic and watery extracts of $Z$. officinale roots in mice was safe and has no toxic effect [28].

The results suggested that sperm parameters have significantly enhanced in both treated groups 50 and/or $100 \mathrm{mg} / \mathrm{kg}$ bw. of water extract. Aleissa (2014) and Hosseini et al., (2016) have suggested that $Z$. officinale roots have an improvement effect on sperm parameters in mice. Also, treated male mice showed a significant reduction of DNA fragmentation of sperms and increased the 
level of serum testosterone compared with the negative control group. This reduction in sperm DNA fragmentation and level of serum testosterone may relate to the antioxidant property and androgenic effect respectively of $Z$. officinale [14, 29]. The reduction in sperm DNA fragmentation may occur as a result of the ability of the bioactive compounds to break the chain reaction of oxidation free radicals; since, sperm DNA fragmentation in diabetic men of reproductive age results from access amount of Reactive Oxygen Species (ROS), which generated from hyperglycemia, [30, 31].

The results of IVF outcomes suggested signification improvement in treated groups compared with the negative control. In negative control the rate of IVF outcomes was very poor this ascribed to the increased DNA fragmentation, reduced sperm motility, decreased sperm ability to bind to zona pellucida and decreased embryonic viability [2]. These findings may shed light on the importance of increasing the rate of IVF outcomes as it possibly increases the chance of pregnancy for diabetic couples. The increased rate of IVF outcomes in treated groups may relate to the reduced sperm DNA fragmentation and enhanced sperm parameters especially the sperm motility rate after treatment with water extract. Simon et al., (2010) have suggested that the anti-oxidative therapy may protect sperm DNA prior to assisted reproductive technique treatment [32].

The data on embryonic developmental rate suggested no significant correlation between improvement of DNA fragmentation and early embryonic development. This may be ascribed that oocytes or embryos may have the capacity to repair sperm of low DNA fragmentation [33]. However this high rate of embryonic development may not assured the development of normal embryo at late stages of pregnancy, since during the early embryonic stages of embryo development (i.e., 4-8 cells) oocyte genome has the dominant role in controlling early development of embryo. Only after this stage, the embryonic genome becomes transcriptional active, with the paternal genome contributing to further embryo development [32]. Nonetheless, further research is required to evaluate the quality for of embryo following IVF at late stages of development.

In conclusion, the data of the current work have highlighted for the first time the potential effect of $Z$. officinale water extract on improving and increasing the rate of IVF outcomes in mice. Such finding may bring benefit and hope for DM male of reproductive age to have children with the help of assisted reproductive techniques. Therefore, further investigations are required to understand the potential effect of the biological activities of bioactive components in this plant which may be useful for diabetic patients who suffer from sexual impotency.

Table (1)

Effect of low and high dose of Zingiber officinale extract on serum testosterone after 35 days treatment of diabetic male mice.

\begin{tabular}{||c||c||}
\hline Group & Testosterone $(\mathrm{ng} / \mathrm{ml})$ level \\
\cline { 2 - 3 } $\begin{array}{c}\text { Positive } \\
\text { Control G1 }\end{array}$ & $2.53 \pm 0.71$ \\
\hline $\begin{array}{c}\text { Negative } \\
\text { Control G2 }\end{array}$ & $1.42 \pm 0.51$ \\
\hline \hline $\begin{array}{c}\text { Low dose } \\
\text { group G3 }\end{array}$ & $2.69 \pm 0.62$ \\
\hline \hline $\begin{array}{c}\text { High dose } \\
\text { group G4 }\end{array}$ & $2.77 \pm 0.69$ \\
\hline
\end{tabular}

Data are presented as Mean \pm SEM $P \leq 0.05$ is significant.

Table (2)

Effect of low and high of Zingiber officinale extract on sperm parameters (sperm count, motility, abnormalities of sperm) after 35 days treatment of diabetic male mice.

\begin{tabular}{|c|c|c|c|}
\hline Groups & $\begin{array}{c}\text { Sperm } \\
\text { count } \\
\left(\times 10^{6} / \mathrm{ml}\right)\end{array}$ & $\begin{array}{c}\text { Sperm } \\
\text { motility (\%) }\end{array}$ & $\begin{array}{c}\text { Sperm } \\
\text { abnormal } \\
\text { morphology } \\
(\%)\end{array}$ \\
\hline $\begin{array}{c}\text { Positive } \\
\text { Control } \\
\text { G1 }\end{array}$ & $8.51 \pm 0.96$ & $70.65 \pm 8.42$ & $23.63 \pm 3.85$ \\
\hline $\begin{array}{c}\text { Negative } \\
\text { Control } \\
\text { G2 } \\
\end{array}$ & $4.62 \pm 0.75$ & $43.35 \pm 5.29$ & $54.72 \pm 5.72$ \\
\hline $\begin{array}{l}\text { Low dose } \\
\text { group G3 }\end{array}$ & $6.44 \pm 0.78$ & $72.61 \pm 8.05$ & $33.63 \pm 2.09$ \\
\hline $\begin{array}{l}\text { High dose } \\
\text { group G4 }\end{array}$ & $7.85 \pm 0.69$ & $85.43 \pm 9.04$ & $27.62 \pm 2.05$ \\
\hline
\end{tabular}

Data are presented as Mean $\pm S E M$

$P \leq 0.05$ is significant. 
Table (3)

Effect of Zingiber officinale extract on sperm DNA fragmentation after 35 days treatment of diabetic male mice.

\begin{tabular}{|c||c|}
\hline Groups & $\begin{array}{c}\text { Rate of sperm DNA } \\
\text { fragmentation (\%) }\end{array}$ \\
\hline \hline $\begin{array}{c}\text { Positive } \\
\text { Control G1 }\end{array}$ & $8.44 \pm 1.21$ \\
\hline $\begin{array}{c}\text { Negative } \\
\text { Control G2 }\end{array}$ & $33.52 \pm 4.76$ \\
\hline \hline $\begin{array}{c}\text { Low dose } \\
\text { group G3 }\end{array}$ & $15.39 \pm 2.08$ \\
\hline $\begin{array}{c}\text { High dose } \\
\text { group G4 }\end{array}$ & $11.42 \pm 1.86$ \\
\hline
\end{tabular}

Data are presented as Mean \pm SEM $P \leq 0.05$ is significant.

Table (4)

Effect of Zingiber officinale extract on percentage of oocyte fertilised and early embryonic development by in vitro fertilisation after 35 days treatment of diabetic male mice.

\begin{tabular}{||c||c||c|}
\hline Group & $\begin{array}{c}\text { Fertilization } \\
(\%)\end{array}$ & $\begin{array}{c}\text { Embryonic } \\
\text { development } \\
(2-4 \text { cells })(\%)\end{array}$ \\
\hline \hline $\begin{array}{c}\text { Positive } \\
\text { Control G1 }\end{array}$ & 63.63 & 64.28 \\
\hline $\begin{array}{c}\text { Negative } \\
\text { Control G2 }\end{array}$ & 41.66 & 60.00 \\
\hline $\begin{array}{c}\text { Low dose } \\
\text { group G3 }\end{array}$ & 59.37 & 63.15 \\
\hline \hline $\begin{array}{c}\text { High dose } \\
\text { group G4 }\end{array}$ & 60.71 & 64.70 \\
\hline
\end{tabular}

Data are presented as Mean \pm SEM $P \leq 0.05$ is significant $j$

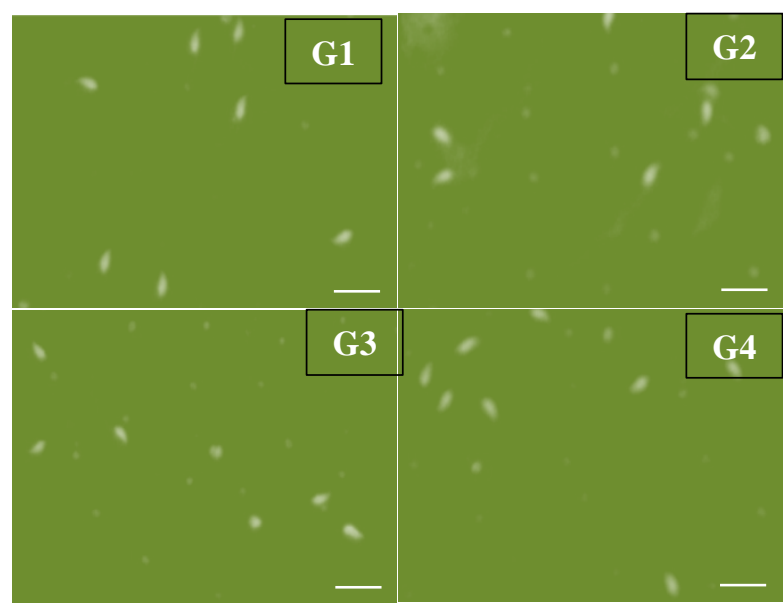

Fig.(1): The Representative florescence images showing the staining of DNA strands using acridine orange stain. Green

florescence indicates the normal double DNA strand, whereas red florescence indicates the single fragmented DNA strand.

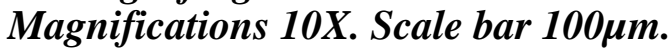

\section{References}

[1] WHO,Global Report on diabetes 2016. http://apps.who.int/iris/bitstream/10665/204 871/1/9789241565257_eng.pdf.

[2] Agbaje I.M., ROGERS D. A., Mcvicar C. M., Mcclure N., Atkinson A. B., Mallidis C. and Lewis S. E. M., "Insulin dependant diabetes mellitus: implications for male reproductive function", Hum Reprod., 22, 1871-1877, 2007.

[3] Wild S., Roglic G., Green A., Sicree R. and King H., "Global prevalence of diabetes: estimates for the year 2000 and projections for 2030", Diabetes Care, 27, 1047-1053, 2004.

[4] Sexton W.J. and J.P. Jarow, "Effect of diabetes mellitus upon male reproductive function”. Urology, 49(4), 508-513, 1997.

[5] Du Plessis S.S., Kashou A.H., Benjamin D.J., Yadav S.P. and Agarwal A., "Proteomics: a subcellular look at spermatozoa", Reprod. Biol. Endocrinol., 9, $1-12,2011$.

[6] Gonzalez-Marin C., Gosalvez J. and Roy R., "Types, causes, detection and repair of DNA fragmentation in animal and human sperm cells", Int J Mol Sci, 2012.

[7 Lewis SEM., "Sperm DNA fragmentation and base oxidation, Genetic Damage in Human Spermatozoa", Springer, 103-116, 2014. 
[8] Benchaib M., Braun V., Lornage J., Hadi S., Salle B., Lejeune H. and Guerin J. F., "Sperm DNA fragmentation decreases the pregnancy rate in an assisted reproductive technique", Hum Reprod., 18(5), 10231028, 2003.

[9] Sergerie M., Laforest G., Bujan L., Bissonnette F. and Bleau G., "Sperm DNA fragmentation: threshold value in male fertility", Hum Reprod., 20(12), 3446-3451, 2005.

[10] Kefer J.C., Agarwal A. and Sabanegh E., "Role of antioxidants in the treatment of male infertility", Inter. J. Uro., 16(5), 449457, 2009.

[11] Ross C., Morriss A., Khairy M., Khalaf Y., Braude P., Coomarasmy A. and ElToukhy T., "A systematic review of the effect of oral antioxidants on male infertility", Reprod Biomed Online., 20(6), 711-723, 2010.

[12] Al-Ahmed, H., Mahood R., Bonev G. and Georgieva S., "Effects of antioxidant (Salvia officinalis L. extract) on in vitro fertilization and micromanipulation intracytoplasmic sperm injection in Albino mice”, Agricult. Sci. and Techno., 4(1), 1519, 2012.

[13] Menezo Y., Evenson D., Cohen M. and Dale B., "Effect of antioxidants on sperm genetic damage", Adv Exp Med Biol, 791, 173-189, 2014.

[14] Hosseini J., Mardimamaghani A., Hosseinifar H., Sadighi Gilani M. A., Dadkhah F. and Sepidarkish M., "The influence of ginger (Zingiber officinale) on human sperm quality and DNA fragmentation: A double-blind randomized clinical trial”, Int J Reprod Biomed (Yazd), 14(8), 533-540, 2016.

[15] Li, Y., Tran V. H., Duke C. C. and Roufogalis B., "Gingerols of Zingiber officinale enhance glucose uptake by increasing cell surface GLUT4 in cultured L6 myotubes", Planta Med, 78(14), 15491555, 2012.

[16] Abdulrazaq, N.B., Cho M. M., Win N. N., Zaman R. and Rahman M. T., "Beneficial effects of ginger (Zingiber officinale) on carbohydrate metabolism in streptozotocininduced diabetic rats", Br J Nutr, 108(7), 1194-1201, 2012.
[17] Oludoyin A.P. and Adegoke S.R., "Effect of Ginger (Zingiber Officinale) Extracts on Blood Glucose in Normal and Streptozotocin--Induced Diabetic Rats", Inter. J. Clinic. Nutri., 2(2), 32-35, 2014.

[18] Sutyarso S., Hendri B., Mohammed K. and Muhartono M., "Rhizome extract of white ginger (Zingiber officinale Roxb) maintains testicular function of aging mice", Inter. J. Nutri. F. Sci. 5(3), 175-178, 2016.

[19] Chougale A.D., "Optimization of Alloxan Dose is Essential to Induce Stable Diabetes for Prolonged Period", Asia. J. Biochem., 2(6), 402-408, 2007.

[20] Kuhad A., Sethi R. and Chopra K., "Lycopene attenuates diabetes-associated cognitive decline in rats", Life Sci., 83(3-4), 128-134, 2008.

[21] WHO, "WHO laboratory manual for the Examination and processing of human semen", 2010.

[22] Tejada R. I., Mitchell J. C., Norman A., Marik J. J. and Friedman S., "A test for the practical evaluation of male fertility by acridine orange (AO) fluorescence", Fertil Steril., 42(1), 87-91, 1984.

[23] Talebi A.R.,Vahidi S., Aflatoonian A., Ghasemi N., Ghasemzaddeh J., Firoozabadi R.d. and Moein M. R., "Cytochemical evaluation of sperm chromatin and DNA integrity in couples with unexplained recurrent spontaneous abortions", Androl., 44 (1 1), 462-470, 2012.

[24] Al-Dujaily S. S. and Al-Saad A. S., "Effect of Glycyrrhiza glabra extract on IVF outcome in mice: experimental model for mammals", BioTech Res Cent., 3, 2, 2009.

[25] Bener, A., Al-Ansari A. A., Zirie M. and Al-Hamaq A. O., "Is male fertility associated with type 2 diabetes mellitus?", Inter urol. and nephrol., 41(4), 777, 2009.

[26] Vignera, S., Condorelli R., Vicari E., Dagat R. and Calogero A. E., "Diabetes mellitus and sperm parameters", J. androl., 33(2), 145-153, 2012.

[27] Rong X., Peng G., Suzukt T., Yang Q., Yamahara J. \& Li, Y., "A 35-day gavage safety assessment of ginger in rats". Reg. Toxicol. and Pharma., 54, 118-123, 2009. 
[28] Shalaby M. A. and Hamowieh A. R., "Safety and efficacy of Zingiber officinale roots on fertility of male diabetic rats", Food Chem Toxicol., 48, 2920-2924, 2010.

[29] Aleissa M. S., "Effect of ginger supplements on some reproductive parameters and Spermatogenesis of mice", Indian J Fund Appl Life Sci., 4, 271-277, 2014.

[30] Mahfouz, R., Sharma R., Thiyagarajan A., Kale V., Gupta S., Sabanegh E. and Agarwal A., "Semen characteristics and sperm DNA fragmentation in infertile men with low and high levels of seminal reactive oxygen species", Fertil.Steril., 94(6), 21412146, 2010.

[31] Robinson, L., Gallos I. D., and Conner S. J., Rajkhowa M., Miller D., Lewis S., Kirkman-Brown J. and Coomarasamy A., "The effect of sperm DNA fragmentation on miscarriage rates: a systematic review and meta-analysis", Hum Reprod., 27(10), 2908-2917, 2012.

[32] Simon, L., Brunborg G., Stevenson M., Lutton D., Mcmanus J. and Lewis S. E., "Clinical significance of sperm DNA damage in assisted reproduction outcome", Hum Reprod., 25(7), 1594-1608, 2010.

[33] Wyrobek, A.J., Eskenazi B., Young S., Arnheim N., Tiemann-Boege I., Jabs E. W., Glaser R. L., Pearson F. S. and Evenson D., "Advancing age has differential effects on DNA damage, chromatin integrity, gene mutations, and aneuploidies in sperm", Proceedings of the National Academy of Sciences of the United States of America, 103(25), 9601-9606, 2006. 